1 3ง $\rfloor$

\title{
III.
}

l'erfuche über die Gefchwindigkeit des Schalls in Wallerdämpfen.

Vom

Dr. Benzenzeng in Dïlieldorf.

Durch die Verfuche von Biot (diele Annal. Neue Folge B. 5. S. 425) war es entfchieden, dals der Schall fich in den Wafferdimplen fortpflanze. Es guulste nur noch beflinınt werden: 1 ) ob er fich auch in Waflerdimpten erzeuge? und dann 3) mir welcher Gelchwindigkeit lich der Schall in ihnen fortplanze?

Das erftere ilt leicht zu entfcheiden. Man braucht zu dem Ende nur eine Orgelpfeife in die Miindung eines kochenden Theekefiels zu litecken, und einen blechernen Cyliuder darüber zu ftitirzen, damit die Dänpfe lich nicht gleich niedelfchlagen. Man erhült dann einen lechr l'chünen Pfeifenton, der aber höher ift als der, den die Pleife in freier Luft giclit.

Die zweite Frage: mit welcher Gel'chwindigkeit fich der Schall in den Düntpfien fortpllanze? künnte nur durch die Claladnilchen Vesluche beflinimt werden, dafs man nänlich genau die Hühe des 


\section{[ $3 r$ ]}

Tons in den Dämpfen mit der Höle des Tons in freier Luft vergliche. Dicle Belimmung fechien um fo interelfanter zu leyn, da wir das lpecilifche Gewicht der Walferdïinpfe zieınlich genau kennen, alfo die beobachtete Gel'chwindigkeit mit der, welche die Theorie giebt, vergleichen, und uns dadurch belehreu künnten, ob der Schall lich in dea Dämpfen nicht vielleicht mit einer Gelchwindigkeir fort: Hlanze, welche der Theorie nüher kümmt, als wir dieles bei den permanent - elaltilchen Luftarten finden. Denn es ift sicht unwahrlcheinlich, dafs die Wïrme, welche nach $L$ a Place durch die Schallichlüge frei werden und die Urfache des Schnellergehens des Schalls feyn foll, bei einex nicht permanent-elaftifchen Flülligkeit, wenigftens zum Theil, auf die Erhaltung des elaliifchen Zultandes verwendet, und daher wieder latent wird, und allo die Gelchwindigkeit des Schalles nicht beIchleunigen kann.

Um diele Verfuche anzuftellen, bediente ich mich eines ganz einfachen Apparats. Er ilt auf Tafel I. in Fig. 3. abgebildet. Ich verltopfie dic Pfeife des Theekeffels mit einem iibergeftürzten Huitclien dampfdicht, und liellte einen blechernen Cylinder auf die Oeffnung des Deckels. In diefen Cylinder war eine Orgelpfeife angebracht, die in atmolphürilcher Luft c gab. Die Pfeife war oben offen und aus dem Principal - Regifter. Der Cylinder war $1 \frac{3}{2}$ Fuls lang und $2 \frac{\pi}{2}$ Zoll weit, hatte unten einen Kand, 


\section{[32]}

der durch zwilchengelegte Leinwand dampfdicht auf den hand des TherkelTrls lichlols, und war oben tuit einem Deckel gelchlollen, in welchem ein Loch war, durch das die Dämpfe einen Ausweg hatten.

Als das Waffer anling zu koche-n, bildeten fich zuerlt nur unvollkommne Tüne; lie wurden aber immer deutlicher. Als es to lange gekocht hatte, dafs ich glaubte, der WalTerilanpf habe alle Luft aus dem Keftel und dem Cylincler vertrieben, und erfulle beide ganz, brachte ich das Thermometer in den Cylinder; es llieg bis $80^{\circ}$ R. Den T'nn, den die Pfeife gab, befiinmte Herr Hölterhof auf dem Monochorde zu d weniger $\frac{1}{8}$, eines Tons. Nachler wurde er aufs neue zu $1+\frac{x}{16}$ und zum dritten Male zu $\mathrm{d}-\mathrm{z}$ to beftimmt; lo dal's marr ihn im Mittel zu d weniger $\frac{z}{T} \mathrm{t}$ eines ganzen Tuns annehmen konnte.

Die Saite war vorher in den Ton c gezogen, den die Orgelpfeife angab, wenn fie nit Luft angeblalen wurde, und die Wärme in Cylindes war $2.5^{\circ} \mathrm{R}$.

Wenn die Gefehisvindigkeit des Schalls für e $=1027$ ifi, lo ilt fie für $d=1157$ und fïr $d-\frac{\pi}{16}$ $=11$ /5. Nun war aber ein Unterlichied in der Temperatur von $55^{\circ} \mathrm{R}$., welches einen Unterl'chied in de:r Gelehwindigkeit des Schalls von 120 Fufs macht. Ift fulglich die Gefuhwindigkeit des Schalls in der Luft $=1027$ par. Ful's, lo mul's fie, dielien Verluchen zu Folge, in gleich warmen Waflerdimpen $1 f^{\prime} 5-120=x 025$ p. Fuls in 1 Secunde [eyn. 


\section{[ 33 ]}

Ich bemerkte bei diefen Verfuchen, dals mein Cylinder fo tief in den Keffel ging, dafs ich nur 2 Zoll Waller im Keffel haben konnte. Das wenige Waffer kochte ftark auf, und gab dem KeITel eine zitternde Bewegung, deren Gerïufch der Deutlichkeit des Tones ['chadete. Ich liefs deswegen den Rand des Cylinders mehr nach unten leetzen, fo dafs ich faft den ganzen Keffel, mit Waffer fitllen konnte. Die zitternde Bewegung beim Kochen fiel nun weg. Auch liel's ich den obern Deckel abnehmen, fo dafs der Cylinder oben ganz offen blieb. Dieles hatte indels keinen Einflul's auf den Ton der Pfeife.

Die Pfeife gab beim Anblalen mit Luft bey $25^{\circ} \mathrm{R}$. wieder c. Der Ton, den die Wafferdämple gaben, war nun fchüner als vorher, und Hr. Hülterho of beltimmte ihn beim erften Verfuche zu $d-\frac{x}{b}$ eines ganzen Tons, und beim zweiten ge. nau d. Das Thermometer flieg jetzt im Cylinder nicht hüher als auf $75^{\circ}$ R. Das Mittel aus beiden Verfuchen ift $d-\frac{3}{x}$.

Diefem Tone entspricht eine Gufchwindigkeit von

hiervon gehn für $50^{\circ} \mathrm{Temp}$. Differenz a 1145 p.F. $\frac{109}{1056}$ die vorigen Verfuche gaben 1025 Mittel aus beiden 2050 p.F.

Man wird alfo nicht bedeutend irren, wenn man annimnit, dals die Gefchwindigkeit des Schalls in Annal. d. Phytik. B. 4*. St. x. J. s\$12. St. 9. 


\section{[ 3 3́r $]$}

den Waflerdämpfen $1030 \mathrm{p}$. Fuls bei $0^{\circ} \mathrm{R}$. in I Secunde ift.

Nach Hm. von Sa uffure verhält lich das Ipecitifche Gewicht des Walferdanpfs zu dern der atmolphärifchen Luft, bei gleichern Druck und gleicher Wärme, wie 7 zu so. Bei $o^{2} R$. und 28 Zoll Druck ift der Wafterdampf allo rágy $3 \mathrm{Mal}$ leichter als Queckfilber. Nach der Newton'lchen Theorie mufs fich folglich der Schall in ihm mit einer Gefchwindigkeit von 1027,6 p. Fufs in I Secunde bewegen. Die eben angeführten Erfahrungen geben ro3o par. Fuls. Aus diefer Uebereinftimmung [cheint zu folgen, dals die freiwerdende Wärme die Gelchwindigkeit des Schalles in den Wallerdïmplen nickt befchleunige, und dafs. fie wabrlcheinlich wieder völlig latent wird, indem Ge darauf verwendet wird, den Dampf in feinem elaftifchen Zuftande zu erhalten.

Schon Newton glaubt, dals die Wafferdämpfe, welche in der Atmolphüre find, die Gefchwindigkeit des Schalls befchleunigen künnen, und dails deswegen der Schall gelchwinder gehe, als er nach der Theorie gehn follte. Als eine zweite Lrlache diefirr grölseren Gelehwindigkeit lah er die felten Theilchen der Luft an, die gleichfan ihre bafis ausunachen, und durch die fich der Schall wie durch fefte Kürper lichnell fortpllanzt. Wenn diele Urfache die einzige wïre, warum der Sthall IGS Fuls mohr Gefchwindigkeit 


\section{[ 55 ]}

hat, als die Theorie angiebt, welche diefe Gefchwindigkeit nur zu 86r p. Fufs findet, fo mïlste ungèfiahr $x^{\frac{x}{2}} \frac{1}{5}$ der Luft aus fellen Theilen beftehen, und man künnte die atmolphärifche Luft nicht weiter als bis auf das 125fache zufammendriicken. Diefes ftreitet nicht mit der Erfahrang, denn $\mathrm{Ha}$ les hat die Luft in einer Bombe nur bis auf das 38fache zulammengedriickt *).

Wenn die Luft fich nur 125 Mal zufammendrücken lielse, fo wïre Franklin's Vermuthung, dafs die fefte Luft der fchwerfte Körper $\int_{e y}$, nicht gegründet, und fie wäre dann noch immer $6 \mathrm{Mal}$ leichter als Waffer. Unlere AtmoIphäre würde dann, wean lie auf das Maximum der Verdichtung kïme, noch 180 Fuls hoch feyn.

Herrn La Place fcheint die Newton'fche Vorftellung von der Urfache des Gelchwindergehens des Schalles grofse Schwierigkeiten zu haben. Er vermuthet, dals die Wärme, welche bei den Cornpreflionen der Schallwellen frei wird, die vorziigliche Urfache fey, warum der Schall nach der Erfahrung 166 Fufs gefchwinder gehe, als dieles

$$
\mathrm{C}_{2}
$$

-) In den Kugeln der Windbüchlen bat man, mehreren glaubwïrdigen Angaben zu Folge, die Verdichtung der Luft bedeurend woiter getrieben, und in rings umlcblolonen, ganı mit Schiefspulver angefülten Räumen, wọrin dieleo entzündet wird, Icheint das fich entwickelnde Gas im. erlien Augenblicke der Wirkung mebr als die swoibundurifacbe Dichrigkeit der atmolphärifeben Lufe su haben. 


\section{[ $3 i$ ]}

die Theorie angiebt. Allein auch diefe Vorftellung hat ihre Schwierigkeiten. Man muls annehmen, dal's hiebei $84^{\circ}$ Wïrme frei wird, und diele Compreflionen müfen allo liehr liark feyn, da bei den Verdichtungen bis aufs Doppelte erft 25 bis $30^{\circ}$ Wirme frei werden.

Herr Biot hat hieriber in dielen Almulen (1. 18. S. 395$)$ verlchiedene Reclinungen mitgetheilt, hat aber keine Unterfuchungen angeltellt, wie ziel Wärme beim plïtzliclıen Verdicliten der J uft dean eigentlich frei werde, und auch nicht, wis viel frei werden mïlle, wenn man aus dicfem liuftande, der auch in den Schallwellen wirkfim lingn foll, jenen Unterlohied von 166 Fuis erklïren wollte, der zwifchen der wirklichen und der theoretiichen Gelchwindigkeit des Schalls in der Atmolphïre Statt finclet. 